\title{
BALANCE AND BEHAVIOR OF CARBON DIOXIDE AT AN URBAN FOREST INFERRED FROM THE ISOTOPIC AND METEOROLOGICAL APPROACHES
}

\author{
Hiroshi Aoki Takahashi ${ }^{1,2} \bullet$ Tetsuya Hiyama $^{3} \bullet$ Eiichi Konohira $^{3} \bullet$ Atsuhiro Takahashi ${ }^{1} \bullet$ \\ Naohiro Yoshida ${ }^{4}$ Toshio Nakamura ${ }^{5}$
}

\begin{abstract}
Diurnal variations in $\delta^{14} \mathrm{C}, \delta^{13} \mathrm{C}$ and the concentration of atmospheric carbon dioxide in an urban forest were measured on 9 February 1999 to discriminate and quantify contributions from different $\mathrm{CO}_{2}$ sources. The biogenic $\mathrm{CO}_{2}$ concentration remained relatively constant throughout the day. However, anthropogenic $\mathrm{CO}_{2}$ concentration fluctuated with the atmospheric $\mathrm{CO}_{2}$ concentration, and seemed to be controlled by wind velocity and the amount of exhaust gases from fossil fuel burning. The vertical profiles of anthropogenic, biogenic, and total $\mathrm{CO}_{2}$ showed a constant concentration within forest during daytime because of the large vertical $\mathrm{CO}_{2}$ influx, strong winds, and neutral atmospheric condition. The biogenic contribution at night decreased from the forest floor upwards with a smooth gradient, while the anthropogenic contribution showed a direct mirror because of the location of respective $\mathrm{CO}_{2}$ sources - the vertical gradient of wind velocity and the horizontal $\mathrm{CO}_{2}$ supply.
\end{abstract}

\section{INTRODUCTION}

Carbon dioxide emissions due to the burning of fossil fuels such as coal and petroleum increase atmospheric $\mathrm{CO}_{2}$ concentration and exert strong influence to the greenhouse effect and $\mathrm{CO}_{2}$ supply to an urban forest. Other human activities such as increasing nutrient status and enhanced temperature (heat island effect) also have a strong influence on urban forests. Hence, understanding the balance and behavior of gaseous $\mathrm{CO}_{2}$ fluxes within an urban forest will help predict how terrestrial ecosystems may respond to global environmental changes. Here we estimate the $\mathrm{CO}_{2}$ contributions from anthropogenic and biogenic sources and determined their vertical profiles in order to understand carbon cycling and storage within the urban forest.

The measurements were carried out in winter, when photosynthesis is low, because photosynthesis uses soil respired $\mathrm{CO}_{2}$, i.e. $\mathrm{CO}_{2}$ recycling disturbs simple physical mixing relationship (Sternberg 1989). Analyses of radioactive and stable carbon isotopes can identify $\mathrm{CO}_{2}$ contributions from different reservoirs (Mook 1980; Zondervan and Meijer 1996). Diurnal variations in the $\mathrm{CO}_{2}$ concentration, $\delta^{14} \mathrm{C}$ and $\delta^{13} \mathrm{C}$ of the urban atmosphere were measured at two levels-just above the forest canopy and at further higher elevation, to compare the relative contributions of each $\mathrm{CO}_{2}$ source. In order to understand carbon supply to the urban forest, the diurnal variations of vertical profiles in the $\mathrm{CO}_{2}$ concentration and $\delta^{13} \mathrm{C}$ of the urban forest atmosphere were measured at 6 heights within the forest.

\section{STUDY SITES AND METHODS}

The study sites are located about $8 \mathrm{~km}$ east of the center of Nagoya City, Aichi Prefecture in Central Japan. Measurements were made from a tower $\left(35^{\circ} 8^{\prime} 57^{\prime \prime} \mathrm{N}, 136^{\circ} 58^{\prime} 28^{\prime \prime} \mathrm{E}\right)$ situated in a secondary deciduous forest growing on a gentle slope and a broadcasting tower (Chukyo TV broadcasting Co. Ltd., $\left.35^{\circ} 8^{\prime} 37^{\prime \prime} \mathrm{N}, 136^{\circ} 58^{\prime} 15^{\prime \prime} \mathrm{E}\right)$. These two sites are referred to as the forest site and the Chukyo TV

\footnotetext{
${ }^{1}$ Department of Earth and Planetary Sciences, Graduate School of Science, Nagoya University, Nagoya 464-8602, Japan

${ }^{2}$ Present affiliation: Research Center for Deep Geological Environments, Geological Survey of Japan, AISI, Tsakuba 305-8567, Japan. Email: h.a.takahashi@ aist.go.jp.

${ }^{3}$ Institute of Hydrospheric-Atmospheric Science, Nagoya University, Nagoya 464-8601, Japan.

${ }^{4}$ Department of Environmental Sciences and Technology, Titech, Yokohama 266-8502, Japan. Also with CREST Project, Japan Science and Technology Corporation.

${ }^{5}$ Center for Chronological Research, Nagoya University, Nagoya 464-8602, Japan
}

(C) 2001 by the Arizona Board of Regents on behalf of the University of Arizona RADIOCARBON, Vol 43, Nr 2B, 2001, p 659-669

Proceedings of the 17 th International ${ }^{14} \mathrm{C}$ Conference, edited by I Carmi and $\mathrm{E}$ Boaretto 
site, respectively. The forest site is located $600 \mathrm{~m}$ east-northeast of the Chukyo TV site. Both tower bases are $66 \mathrm{~m}$ above the sea level. The sampling ports were set at 23.75, 19.00, 14.75, 9.10, 5.60 and $1.55 \mathrm{~m}$ at the forest site, and at $85 \mathrm{~m}$ at the Chukyo TV site. The top canopy is about $12-18 \mathrm{~m}$, although the study was carried out during the leafless period for the oak trees, which are dominant species in the forest. On the tower of the site meteorological instruments were installed. Ten-minute mean values of wind speed, air temperature, relative humidity, $10 \mathrm{~Hz}$ fluctuations in the horizontal and vertical wind speed components, and air temperature were measured. Atmospheric stability can be estimated using the parameter of Obukhov's length $(L)$ to be represented as non-dimensional parameter of $z / L$ (Brutsaert 1982), where $z$ is the height on which the value of $L$ is determined. Positive and negative values of $z / L$ indicate stable and unstable atmospheric conditions, respectively. However, the atmosphere can be defined as having a neutral condition when $z / L$ ranges from -1 to 1. The $\mathrm{CO}_{2}$ fluxes above the forest canopy were calculated using the eddy correlation technique (Kaimal and Finnigan 1994), using the fluctuations in wind speed and $\mathrm{CO}_{2}$ concentration obtained from a non-dispersive infrared absorption spectrometer, NDIR (KCO-100). The $\mathrm{CO}_{2}$ efflux from the soil surface (soil respiration) was measured using a closed chamber system connected to a NDIR (LI-6262). On the Chukyo TV site ( $85 \mathrm{~m}$ ), wind speed, air temperature, and relative humidity were obtained with an average of 10 minutes.

Air sampling was started at 0:00 on 9 February 1999, and carried out at interval of $3 \mathrm{hr}$ at night and $2 \mathrm{hr}$ in daytime at the forest site; $6 \mathrm{hr}$ at night and $3 \mathrm{hr}$ in daytime at the Chukyo TV site. The air was collected in a $10 \mathrm{~L}$ plastic or a $20 \mathrm{~L}$ aluminized plastic bag. The $\mathrm{CO}_{2}$ concentration was measured with a NDIR (LI-6262) as soon as the air sampling was finished. $\mathrm{CO}_{2}$ was cryogenically trapped from the sampled air within a few hours after sampling. Graphite targets (Kitagawa et al. 1993) were prepared from a sample and a standard (NIST Oxalic acid, Hox-II) for ${ }^{14} \mathrm{C}$ analysis with a Tandetron accelerator mass spectrometer at the Center for Chronological Research, Nagoya University (Nakamura et al. 1985). Stable carbon isotopic ratios were measured on an isotope-ratio mass spectrometer (Finnigan MAT 252) at the same laboratory. The $\delta^{13} \mathrm{C}$ values are represented with respect to the PDB standard (Craig 1957), using the NBS-19 standard. A correction of $0.2 \%$ o for $\mathrm{N}_{2} \mathrm{O}$ contamination was applied to the $\delta^{13} \mathrm{C}$ calculations (Mook and Jongsma 1987).

Atmospheric $\mathrm{CO}_{2}$ in this study area is mainly a mixture of $\mathrm{CO}_{2}$ from the free atmosphere and that emitted from anthropogenic and biogenic sources. A mixing model for the three isotopically distinct gases is given by

$$
I_{S} C_{S}=I_{A} C_{A}+I_{F} C_{F}+I_{B} C_{B}=I_{A} C_{A}+I_{F}\left(C_{S}-C_{A}\right) f+I_{B}\left(C_{S}-C_{A}\right)(1-f)
$$

where I is the carbon isotopic value, i.e. $\delta^{14} \mathrm{C}$ or $\delta^{13} \mathrm{C}$, $\mathrm{C}$ is concentration. The suffix $\mathrm{S}$ refers to a specific sample in the present study, A is the background (i.e. free) atmosphere, F is fossil fuels (anthropogenic) component and $\mathrm{B}$ is the soil respiration (biogenic) component. The fraction of the fossil fuel component to the total excess $\mathrm{CO}_{2}$ concentration above the background level $\left(\mathrm{C}_{\mathrm{S}}-\mathrm{C}_{\mathrm{A}}\right)$ is $\mathrm{f}$, where $0 \leq \mathrm{f} \leq 1$. In the present study, ${ }^{14} \mathrm{C}$ isotopic value was represented not by $\Delta{ }^{14} \mathrm{C}$ but by $\delta^{14} \mathrm{C}$, since the discussion of carbon behavior in the present study was explained by the atmospheric mixing of $\mathrm{CO}_{2}$ released from each source without isotopic fractionation. The end-member values of respective sources were also represented by $\delta^{14} \mathrm{C}$ in the present study. This logic is similar to the analysis by Zondervan and Meijer (1996) that used ${ }^{14} \mathrm{C} /{ }^{12} \mathrm{C}$ ratio. $\delta^{14} \mathrm{C}_{\mathrm{F}}$ is defined as $-1000 \%$ o theoretically. In study area, $\delta^{14} \mathrm{C}_{\mathrm{B}}$ is given as $-30 \pm 9 \%$, $\delta^{13} \mathrm{C}_{\mathrm{A}}$ is $-7.8 \pm 0.1 \%$, $\delta^{13} \mathrm{C}_{\mathrm{B}}$ is $-27.3 \pm 0.4 \%$, and $\delta^{13} \mathrm{C}_{\mathrm{F}}$ is $-32.3 \pm 1.0 \%$ (Takahashi 2001). The value of $\delta^{14} \mathrm{C}_{\mathrm{A}}$ is given as $136 \pm 3 \%$ (Levin and Kromer 1997), and $C_{A}$ value is 370.42ppm (Uhse et al. 1998), which were observed in Germany in the winter season of 1996 and 1997. The $\delta^{14} \mathrm{C}_{\mathrm{A}}$ was corrected for the decline during 2 years, i.e. 
from 1997 to the observation year in the present study, using the exponential curve reported by Levin and Kromer (1997) to be $124 \%$ o. $\mathrm{C}_{\mathrm{A}}$ was also corrected using the increasing trend of $1.43 \mathrm{ppm} /$ year for 1981-92 at Mauna Loa Station (Conway et al. 1994) to be 373.28ppm. Although the present study area (Japan) is far from Germany, it is possible to use these background values in Equation (1) for the following reason: $\mathrm{CO}_{2}$ concentration and $\delta^{14} \mathrm{C}$ values of the background (free) atmosphere in a specific area, e.g. Japan and Germany, can be explained by the simple physical $\mathrm{CO}_{2}$ mixing between global background and fossil fuel components, since the $\delta^{14} \mathrm{C}$ value of $\mathrm{CO}_{2}$ derived from fossil fuels, which currently controls the discrepancies in $\mathrm{CO}_{2}$ concentration and $\delta^{14} \mathrm{C}$ in the atmosphere from global background, always shows constant to be $-1000 \%$. Over and above, the background $\mathrm{CO}_{2}$ concentration shows similar values at both areas (Uhse et al. 1998, NIES-Japan http:// www-cger.nies.go.jp/moni/gbm-data.html, accessed on 4 October 2000).

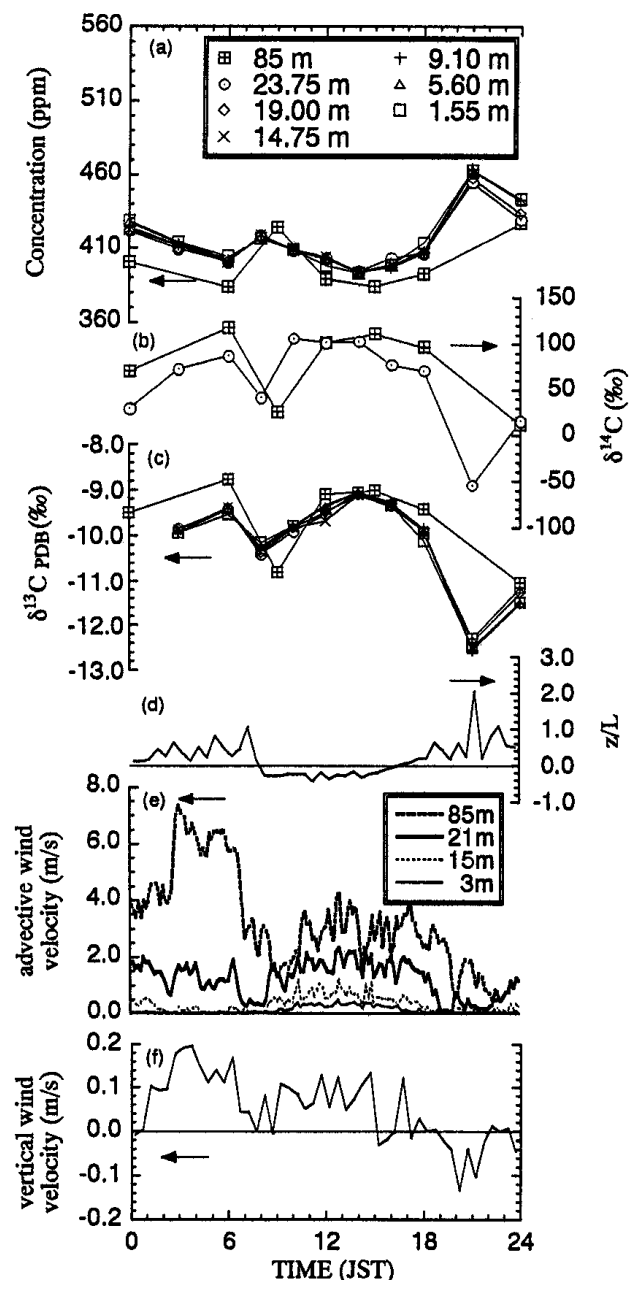

Figure 1 Diurnal variations of concentration (a), $\delta^{14} \mathrm{C}(\mathrm{b})$ and $\delta^{13} \mathrm{C}$ (c) of the atmospheric $\mathrm{CO}_{2}$ sampled at 7 heights; $85 \mathrm{~m}$ (squared plus), $23.75 \mathrm{~m}$ (circle), $19.00 \mathrm{~m}$ (diamond), $14.75 \mathrm{~m}$ (cross), $9.10 \mathrm{~m}$ (plus), $5.60 \mathrm{~m}$ (triangle) and $1.55 \mathrm{~m}$ (square). Also shown are the horizontal wind velocity (d) at $85 \mathrm{~m}$ (bold dotted line), $21 \mathrm{~m}$ (bold solid line), $15 \mathrm{~m}$ (dotted line), and $3 \mathrm{~m}$ (solid line), and $\mathrm{z} / \mathrm{L}$ obtained at $21 \mathrm{~m}(\mathrm{e})$ 


\section{RESULTS AND DISCUSSION}

\section{Variation of Concentration, $\delta^{14} \mathrm{C}$ and $\delta^{13} \mathrm{C}$ of the Atmospheric $\mathrm{CO}_{2}$ and Estimate Results}

Diurnal variations in the vertical profiles of $\mathrm{CO}_{2}$ concentration, $\delta^{14} \mathrm{C}, \delta^{13} \mathrm{C}$ and meteorological indices are shown in Figure 1 above (All observed data of $\mathrm{CO}_{2}$ concentration, $\delta^{14} \mathrm{C}$, and $\delta^{13} \mathrm{C}$ are listed in the Appendix). $\mathrm{CO}_{2}$ concentration is generally low during the daytime and high during the night. This tendency was similar to that reported in the previous studies (Aikawa et al. 1995). Diurnal variations in $C_{F}$ and $C_{B}$ from the respective sampling sites at $23.75 \mathrm{~m}$ and $85 \mathrm{~m}$ were estimated from equation 1 using $\mathrm{CO}_{2}$ concentration and $\delta^{14} \mathrm{C}$ (Figure 1a-b), and are shown in Figure 2. The $\mathrm{CO}_{2}$ concentration of the respective components at $85 \mathrm{~m}$ was lower than that at $23.75 \mathrm{~m}$. This stratification is consistent with the fact that $\mathrm{CO}_{2}$ was released nearby/on the land surface. Large fluctuations were observed for $\mathrm{C}_{\mathrm{F}}$ along $\mathrm{C}_{\mathrm{S}}$ fluctuations, whereas $\mathrm{C}_{\mathrm{B}}$ remained relatively constant throughout the day. This indicated that the fluctuation in $\mathrm{CO}_{2}$ concentration of the urban atmosphere was mainly explained by anthropogenic $\mathrm{CO}_{2}$ emission.

Figure 2 Diurnal variations of $\mathrm{CO}_{2}$ concentration from the anthropogenic $\left(\mathrm{C}_{\mathrm{F}}\right)$ and biogenic $\left(\mathrm{C}_{\mathrm{B}}\right)$ sources at $85 \mathrm{~m}$ in the Chukyo TV site (a) and at $23.75 \mathrm{~m}$ in the forest site (b) $\mathrm{CO}_{2}$ concentrations from two sources were shown using different axes.

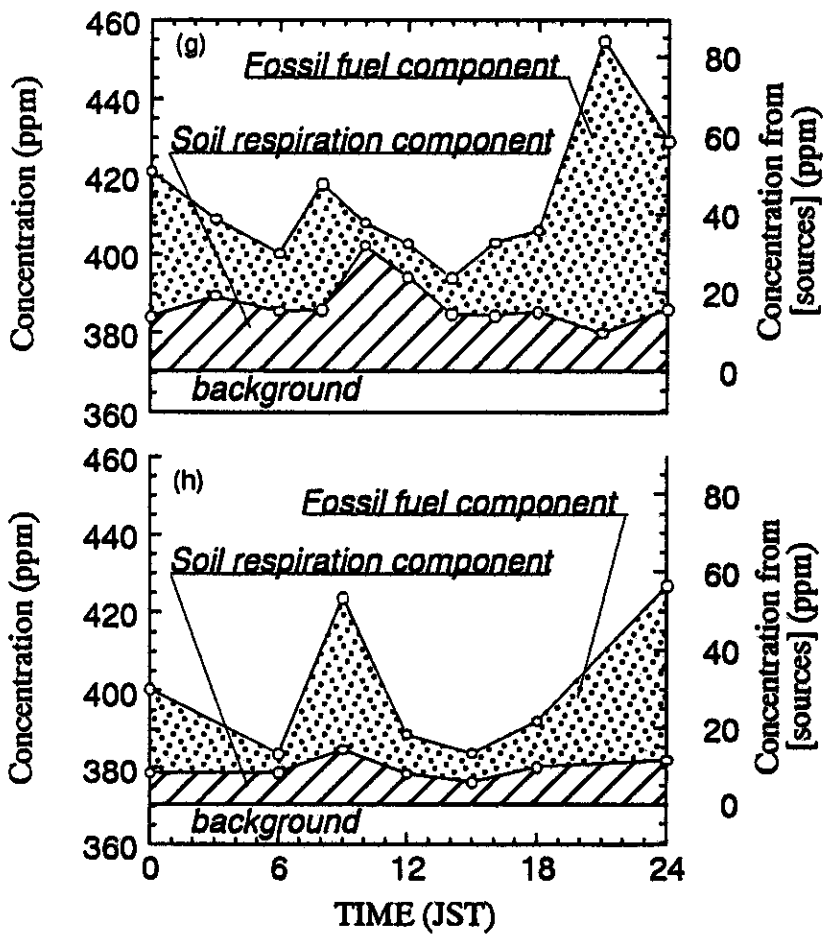

$\mathrm{C}_{\mathrm{F}}$ and the percentage of $\mathrm{C}_{\mathrm{F}}$ to $\mathrm{C}_{\mathrm{S}}$ (in parentheses) ranged from 2-70 ppm (0.4-15.5\%) at $23.75 \mathrm{~m}$, and from $1-41 \mathrm{ppm}(0.2-9.5 \%)$ at $85 \mathrm{~m}$. These values are very similar to the result from Poland, which was reported to be circa 27 ppm for February 1983-1994 by Kuc and Zimnoch (1998). In the present study area, a large $\mathrm{CO}_{2}$ emission from automobiles affected the increment of ambient $\mathrm{CO}_{2}$ concentration. Its influence can not be evaluated in this study, but $\mathrm{CO}_{2}$ emission from human activities altogether may be considered as the principal contributor to the $\mathrm{CO}_{2}$ increase (Aikawa et al. 1995). $C_{B}$ and the percentage of $C_{B}$ to $C_{S}$ (in parentheses) ranged from 11-33 ppm (2.4-8.2\%) at $23.75 \mathrm{~m}$, and from $7-16 \mathrm{ppm}(1.9-3.7 \%)$ at $85 \mathrm{~m}$. $\mathrm{C}_{\mathrm{B}}$ remained relatively constant throughout the 
day, at about $15 \mathrm{ppm}(23.75 \mathrm{~m})$ and about $10 \mathrm{ppm}(85 \mathrm{~m})$. The constant contribution of $\mathrm{C}_{\mathrm{B}}$ is reflected by a constant $\mathrm{CO}_{2}$ flux from the soil. According to the $\mathrm{CO}_{2}$ flux measurement using a closed chamber observation in the present study, its diurnal variation being only $0.20 \mu \mathrm{mol} / \mathrm{m}^{2} / \mathrm{sec}$. with a daily average at the forest site of $0.70 \mu \mathrm{mol} / \mathrm{m}^{2} / \mathrm{sec}$. This average value of $\mathrm{CO}_{2}$ flux from soil surface corresponded to $2.7 \mathrm{ppm} /$ hour, if the respired $\mathrm{CO}_{2}$ was distributed equally within forest atmosphere of $23.75 \mathrm{~m}$ height. Thus, mean residence time of soil respired $\mathrm{CO}_{2}$ might be considered several hours on daily average. We can not assess whether this residence time was reasonable or not, since the rate of air transportation could not be obtained from the meteorological analyses.

\section{Diurnal Variations of $\mathrm{CO}_{2}$ Concentration and Atmospheric Condition}

Air transport from ambient to free atmosphere, which is mainly controlled by the atmospheric stability and wind velocity, causes the diurnal variations of $\mathrm{CO}_{2}$ concentration. $\mathrm{CO}_{2}$ concentration in an urban atmosphere does not return to the background level under low wind or stable atmospheric conditions. Atmospheric stability on the observation day in this study was almost under neutral conditions $(-1 \leq \mathrm{z} / \mathrm{L} \leq 1)$ throughout the day (Figure $1 \mathrm{e})$. Hence, the atmospheric stability does not seem to have any influence on the diurnal variations in $\mathrm{CO}_{2}$ concentration.

We compared $\mathrm{CO}_{2}$ concentrations of the respective components, i.e. $\mathrm{C}_{\mathrm{S}}, \mathrm{C}_{\mathrm{F}}$ and $\mathrm{C}_{\mathrm{B}}$, with the wind velocity (Figure 1d). Wind velocity show a negative correlation against both values of $\mathrm{C}_{S}(\mathrm{r}=-0.80)$ and $\mathrm{C}_{\mathrm{F}}(\mathrm{r}=-0.76)$ with almost identical coefficients. $\mathrm{C}_{\mathrm{B}}$ at the Chukyo TV site showed a negative correlation against wind velocity $(\mathrm{r}=-0.61)$, whereas that at the forest site showed no distinct correlation $(r=0.28)$. The correlation between $C_{S}, C_{F}$ and wind velocity indicates that air transportation controls the diurnal variation. On the contrary, $\mathrm{C}_{\mathrm{B}}$ showed another trend. At the forest site, the $\mathrm{CO}_{2}$ from soil respiration was directly supplied from the nearby forest floor, therefore, the diurnal variation of $C_{B}$ at the forest canopy is not affected by wind velocity at the canopy height. $\mathrm{C}_{\mathrm{B}}$ at the forest site increased when a light wind started blowing at the height of $3 \mathrm{~m}$ (Figure 1d). Probably, $\mathrm{CO}_{2}$ from soil respiration at the forest site had accumulated just on the soil surface (e.g. below $0.3 \mathrm{~m}$, Buchmann et al. 1997) until the breeze started. At the Chukyo TV site, the $\mathrm{CO}_{2}$ from soil respiration was thought to be supplied from the wider urban area. Therefore, it seems that the circulation behavior of $\mathrm{CO}_{2}$ from soil respiration at a height of $85 \mathrm{~m}$ in the atmosphere is almost identical with $\mathrm{CO}_{2}$ from other components.

\section{Vertical Profiles of Anthropogenic and Biogenic $\mathrm{CO}_{2}$ within the Forest}

Diurnal changes of vertical profiles of the fossil fuel and the soil respiration components within the forest were estimated from equation 1 using $\mathrm{CO}_{2}$ concentration and $\delta^{13} \mathrm{C}$ (Figure 1a, c) that were measured within the forest. The vertical mean profiles of $\mathrm{C}_{F}, \mathrm{C}_{\mathrm{B}}$ and $\mathrm{C}_{\mathrm{S}}$ during the daytime (8:00 to 16:00) and night (3:00 to 6:00 and 18:00 to 24:00) are shown in Figure 3. Since $\delta^{14} \mathrm{C}$ was not measured for all vertical samples, the contributions of the respective components within a forest was estimated using $\mathrm{CO}_{2}$ concentration and $\delta^{13} \mathrm{C}$. Thus, the large errors for the estimated contributions are unavoidable because the $\delta^{13} \mathrm{C}$ disparity between the fossil fuel and soil respiration components is small. At night, there is a larger gradient of $C_{B}$ than $C_{F}$, whereas $C_{B}$ and $C_{F}$ have constant vertical contributions during the daytime. Diurnal change in gradient of the vertical profile of $\mathrm{CO}_{2}$ within the forest (Figure 3) is strongly influenced by the wind velocity (Figure 1d). At night, $\mathrm{C}_{\mathrm{B}}$ has the decrease trend vertically from the forest floor to the canopy, but $\mathrm{C}_{\mathrm{F}}$ has the increase trend. These indicate that $\mathrm{CO}_{2}$ from soil respiration was directly supplied to the forest atmosphere and $\mathrm{CO}_{2}$ source of fossil fuel component was not located within the forest. Moreover, the influence of $\mathrm{CO}_{2}$ from fossil fuel component was stronger at the higher levels in the forest at night. The vertical constant concentration of respective components during the daytime indicates that the forest atmosphere was mixed well vertically. 


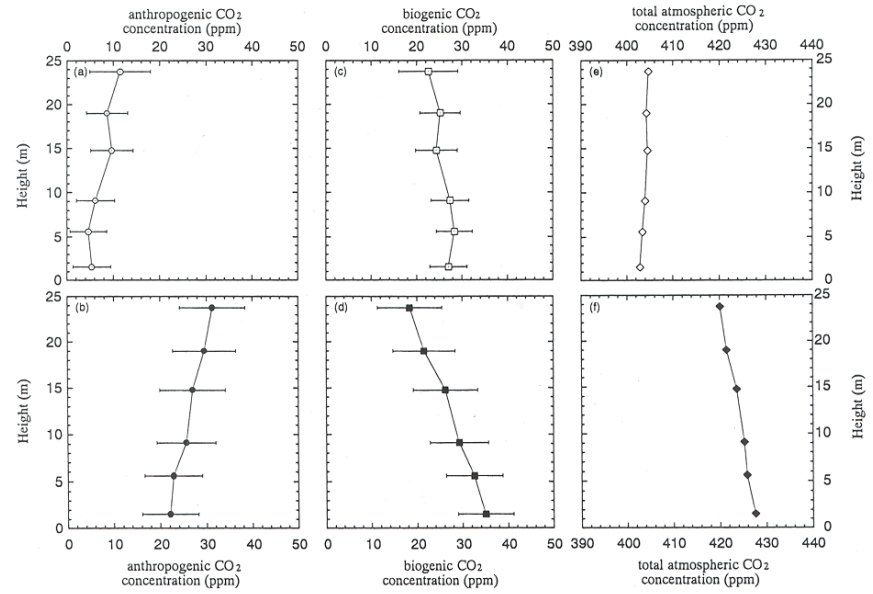

Figure 3 Vertical profiles of the mean $\mathrm{CO}_{2}$ concentration from anthropogenic $\left(\mathrm{C}_{\mathrm{F}}: \mathrm{a}, \mathrm{b}\right)$ and biogenic $\left(\mathrm{C}_{\mathrm{B}}: \mathrm{c}, \mathrm{d}\right)$ sources at the daytime (open symbols) and at night (closed symbols). Also shown is the concentration of total atmospheric $\mathrm{CO}_{2}\left(\mathrm{C}_{\mathrm{S}}\right)$ at the daytime (e) and at night (f).

We attempted analysis based on meteorological results for $\mathrm{CO}_{2}$ balance at the forest in order to support the above discussion based on vertical profiles, since the vertical profiles within the forest have a large error caused by the estimation technique. The rate of $\mathrm{CO}_{2}$ concentration change within the forest atmosphere $(\Delta \mathrm{Q})$ can be given by

$$
\Delta \mathrm{Q}=\mathrm{V}+\mathrm{A}+\mathrm{R}+\mathrm{P}
$$

where $\mathrm{V}$ is vertical $\mathrm{CO}_{2}$ flux at the forest canopy from outside the forest, $\mathrm{A}$ is the advective $\mathrm{CO}_{2}$ flux from outside the forest horizontally, $\mathrm{R}$ is $\mathrm{CO}_{2}$ evolved by respiration and $\mathrm{P}$ is photosynthesis. $\mathrm{V}$ was calculated from the fluctuations in wind speed and $\mathrm{CO}_{2}$ concentration by the eddy correlation technique (Kaimal and Finnigan 1994). The $\Delta \mathrm{Q}$ value was computed from the diurnal variations of $\mathrm{CO}_{2}$ concentration profiles. $\mathrm{CO}_{2}$ flux from soil (R) was measured to be ranged from 2.4 to $3.1 \mathrm{ppm} / \mathrm{hr}$ using a chamber styled observation. $\mathrm{P}$ is assumed to be negligible. Thus A can be estimated. Diurnal variation of $\mathrm{V}, \mathrm{A}$, and $\Delta \mathrm{Q}$ is shown in Figure 4.

$\mathrm{CO}_{2}$ was supplied horizontally and escaped vertically at night, whereas the $\mathrm{CO}_{2}$ movement during daytime showed opposite direction (Figure 4). The constant concentration of fossil fuel and soil respiration components in vertical profiles within the forest during daytime (Figure 3) might be caused by large vertical $\mathrm{CO}_{2}$ influx and horizontal $\mathrm{CO}_{2}$ efflux (Figure 4); these exert influence on the vertical air mixing. The strong wind (Figure 1d) and neutral atmospheric condition (Figure 1e) also caused the strong vertical atmospheric mixing within and above the forest. At night, $\mathrm{CO}_{2}$ was mainly supplied by horizontally (Figure 4). This horizontal influx, i.e. incoming influence, might be stronger at the higher levels in the forest, since the wind velocity show a gradual change vertically (Figure 1d). The smooth vertical profiles within the forest of the respective components at night (Figure 3) also suggested that the horizontal influx of $\mathrm{CO}_{2}$ to the forest was changed gradually along the height level. The discussion of $\mathrm{CO}_{2}$ behavior at the urban forest based on $\mathrm{CO}_{2}$ balance and meteorological results were consistent with analysis from the isotopic approach. Hence, it is possible to consider that the vertical profiles in $\mathrm{CO}_{2}$ concentration of respective components, $\mathrm{C}_{\mathrm{F}}$ and $\mathrm{C}_{\mathrm{B}}$, within the forest (Figure 3 ) have some specific trends as discussed above, although the estimation error is large. 


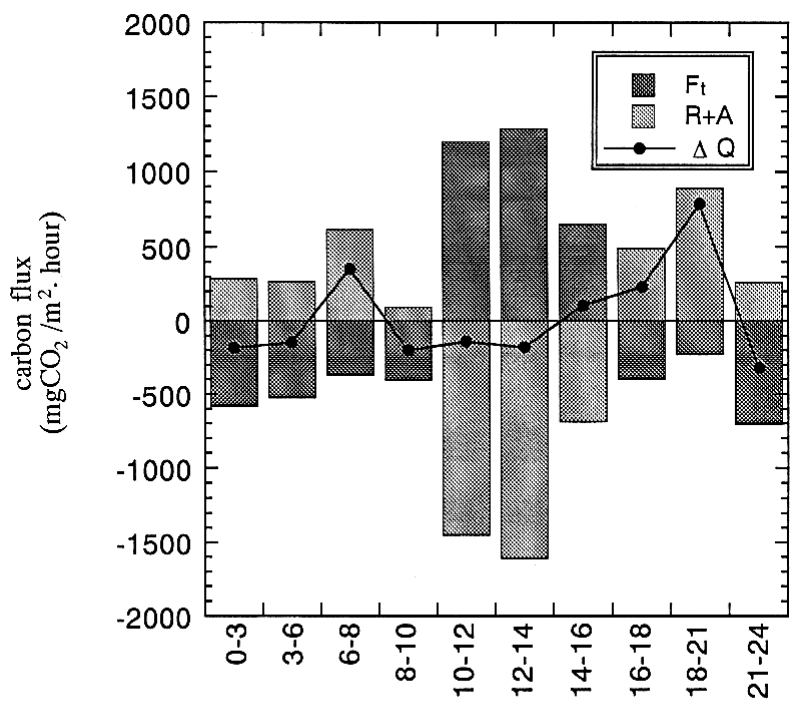

Time (JST)

Figure 4 Diurnal variation of vertical $\mathrm{CO}_{2}$ influx at the top of the forest canopy $(\mathrm{V})$, the advective $\mathrm{CO}_{2}$ influx from outside the forest $(\mathrm{A})$, and the rate of $\mathrm{CO}_{2}$ concentration change $(\Delta \mathrm{Q})$. The positive and negative values show $\mathrm{CO}_{2}$ influx and efflux, respectively.

\section{CONCLUSIONS}

The diurnal and vertical variations of the anthropogenic and the biogenic contributions in atmospheric $\mathrm{CO}_{2}$ at an urban area were estimated in winter season using concentration, $\delta^{14} \mathrm{C}$ and $\delta^{13} \mathrm{C}$ of the atmospheric $\mathrm{CO}_{2}$. The diurnal variation in the atmospheric $\mathrm{CO}_{2}$ concentration, which is low during the daytime and high during the night, was mainly controlled by wind velocity with the neutralcondition of atmospheric stability and was influenced by the amount of $\mathrm{CO}_{2}$ emitted from fossil fuel burning. The contribution of the soil respiration component decreases vertically from the forest floor to the canopy, but that of the fossil fuel component increased. The mean residence time of soil respired $\mathrm{CO}_{2}$ was suggested to be several hours. The meteorological observation and $\mathrm{CO}_{2}$ budget analysis at the forest indicate that $\mathrm{CO}_{2}$ was supplied horizontally and escaped vertically through the forest canopy at night, whereas the $\mathrm{CO}_{2}$ movement during daytime moved in the opposite direction. These results are consistent with the trends of the vertical profiles in the anthropogenic, biogenic, and total $\mathrm{CO}_{2}$ concentrations.

\section{ACKNOWLEDGMENTS}

We are grateful to Dr Atsuko Sugimoto of Kyoto University for her advice and encouragement. We thank Dr Talat Ahmad of Nagoya University and Dr M Satish Kumar of Shizuoka University for correcting the English version of the manuscript. We are also grateful to Dr Masayo Minami and $\mathrm{Mr}$ Hideyuki Oguri of Nagoya University for their help with air sampling, and to the Chukyo TV broadcasting Co Ltd for their kind permission to use the broadcasting tower for the air sampling. This work was financially supported by grants from the Ministry of Education, Science, Sports and Culture, Japan (Nos. 11213209; IGBP-MESSC 2nd term and 10144103), and a Sasakawa Scientific Research Grant from the Japan Science Society (No. 10-258K). 


\section{REFERENCES}

Aikawa M, Yoshikawa K, Tomida M, Aotsuka F, Haraguchi H. 1995. Continuous monitoring of the carbon dioxide concentration in the urban atmosphere of Nagoya. 1991-1993. Analytical Sciences 11:357-62.

Brutsaert W. 1982. Evaporation into the atmosphere. Dordrecht: Kluwer Academic Publishers. p 299.

Buchmann N, Kao W-Y, Ehleringer J. 1997. Influence of stand structure on carbon-13 of vegetation, soils, and canopy air within deciduous and evergreen forests in Utah, United States. Oecologia 110:109-19.

Conway TJ, Tans PP, Waterman LS, Thoning KW, Kitzis DR, Masarie KA, Zhang N. 1994. Evidence for interannual variability of the carbon cycle from the $\mathrm{Na}$ tional Oceanic and Atmospheric Administration/Climate Monitoring and Diagnostics Laboratory Global Air Sampling Network. Journal of Geophysical Research 99(D11):22831-55.

Craig H. 1957. Isotopic standards for carbon and oxygen and correction factors for mass-spectrometric analysis of carbon dioxide. Geochimica et Cosmochimica Acta 12:133-49.

Kaimal JC, Finnigan JJ. 1994. Atmospheric boundary layer flows. Oxford University Press. p 289.

Kitagawa H, Masuzawa T, Nakamura T, Matsumoto E. 1993. A batch preparation method for graphite targets with low background for AMS ${ }^{14} \mathrm{C}$ measurements. $R a-$ diocarbon 35(2):295-300.

Kuc T, Zimnoch M. 1998. Changes of the $\mathrm{CO}_{2}$ sources and sinks in a polluted urban area (southern Poland) over the last decade, derived from the carbon isotope composition. Radiocarbon 40(1):417-23.

Mook WG. 1980. The effect of fossil fuel and biogenic
$\mathrm{CO}_{2}$ on the ${ }^{13} \mathrm{C}$ and ${ }^{14} \mathrm{C}$ content of atmospheric carbon dioxide. Radiocarbon 22(2):392-7.

Mook WG, Jongsma J. 1987. Measurement of the $\mathrm{N}_{2} \mathrm{O}$ correction for ${ }^{13} \mathrm{C} /{ }^{12} \mathrm{C}$ ratios of atmospheric $\mathrm{CO}_{2}$ by the removal of $\mathrm{N}_{2} \mathrm{O}$. Tellus 39B:96-9.

Nakamura T, Nakai N, Sakase T, Kimura M, Ohishi S, Taniguchi M, Yoshioka S. 1985. Direct detection of radiocarbon using accelerator techniques and its application to age measurements. Japanese Journal of Applied Physics 24:1716-23.

Levin I, Kromer B. 1997. Twenty years of high precision atmospheric ${ }^{14} \mathrm{CO}_{2}$ observations at Schauinsland station, Germany. Radiocarbon 39(2):205-18.

Sternberg LSL. 1989. A model to estimate carbon dioxide recycling in forests using ${ }^{13} \mathrm{C} /{ }^{12} \mathrm{C}$ ratios and concentrations of ambient carbon dioxide. Agricultural and Forest Meteorology 48:163-73.

Takahashi HA. 2001. Behavior of carbon dioxide in an urban forest inferred from the stable and radioactive carbon isotopic analysis [PhD thesis]. Graduate School of Science, Nagoya University, Japan. 205 p.

Uhse K, Schmidt M, Levin I. 1998. Atmospheric $\mathrm{CO}_{2}$ records from sites in the UBA air sampling network In: Trends: A Compendium of Data on Global Change [WWW document]. Carbon Dioxide Information Analysis Center, Oak Ridge National Laboratory, Oak Ridge, Tennessee. URL: http://cdiac.esd.ornl.gov/ftp/ trends/co2/schauinsland.co2. Accessed 28 May 1999.

Zondervan A, Meijer HAJ. 1996. Isotopic characterisation of $\mathrm{CO}_{2}$ sources during regional pollution events using isotopic and radiocarbon analysis. Tellus 48B(4):601-12. 


\section{APPENDIX}

Table 1 Measured values of concentration, $\delta^{14} \mathrm{C}$ and $\delta^{13} \mathrm{C}$ in atmospheric $\mathrm{CO}_{2}$ (height No. 1: $23.75 \mathrm{~m} ; 2: 19.00 \mathrm{~m}, 3: 14.75 \mathrm{~m}, 4: 9.10 \mathrm{~m}, 5: 5.60 \mathrm{~m}, 6: 1.55 \mathrm{~m}$ )

\begin{tabular}{|c|c|c|c|}
\hline $\begin{array}{c}\text { Time-height } \\
\text { no. }\end{array}$ & $\begin{array}{l}\text { Concentration } \\
\quad(\mathrm{ppm})\end{array}$ & $\delta^{14} \mathrm{C}(\%)$ & $\delta^{13} \mathrm{C}(\% o)$ \\
\hline \multicolumn{4}{|l|}{ Forest site } \\
\hline $0-1$ & 421.6 & $30 \pm-7$ & \\
\hline $0-2$ & 421.6 & & \\
\hline $0-3$ & 422.5 & & \\
\hline $0-4$ & 423.9 & & \\
\hline $0-5$ & 427.7 & & \\
\hline $0-6$ & 428.4 & & \\
\hline $3-1$ & 409.5 & $74 \pm-10$ & -9.55 \\
\hline $3-2$ & 409.6 & & -9.56 \\
\hline $3-3$ & 411.4 & & -9.59 \\
\hline $3-4$ & 412.3 & & -9.64 \\
\hline $3-5$ & 413.2 & & -9.58 \\
\hline $3-6$ & 414.0 & & -9.64 \\
\hline $6-1$ & 400.5 & $88 \pm-3$ & -9.11 \\
\hline $6-2$ & 400.6 & & -9.11 \\
\hline $6-3$ & 400.6 & & -9.09 \\
\hline $6-4$ & 401.4 & & -9.12 \\
\hline $6-5$ & 402.5 & & -9.12 \\
\hline $6-6$ & 404.3 & & -9.23 \\
\hline $8-1$ & 418.4 & $42 \pm-9$ & -10.13 \\
\hline $8-2$ & 418.4 & & -10.10 \\
\hline $8-3$ & 418.7 & & -10.08 \\
\hline $8-4$ & 417.7 & & -10.01 \\
\hline $8-5$ & 417.2 & & -9.96 \\
\hline $8-6$ & 416.2 & & -9.86 \\
\hline $10-1$ & 408.5 & $107 \pm-6$ & -9.61 \\
\hline $10-2$ & 408.1 & & -9.53 \\
\hline $10-3$ & 408.8 & & -9.54 \\
\hline $10-4$ & 408.2 & & -9.50 \\
\hline $10-5$ & 408.4 & & -9.50 \\
\hline $10-6$ & 408.9 & & -9.50 \\
\hline
\end{tabular}


Table 1 Measured values of concentration, $\delta^{14} \mathrm{C}$ and $\delta^{13} \mathrm{C}$ in atmospheric $\mathrm{CO}_{2}$ (height No. 1: $23.75 \mathrm{~m} ; 2: 19.00 \mathrm{~m}, 3: 14.75 \mathrm{~m}, 4: 9.10 \mathrm{~m}, 5: 5.60 \mathrm{~m}, 6: 1.55 \mathrm{~m}$ )

\begin{tabular}{|c|c|c|c|}
\hline $\begin{array}{l}\text { Time-height } \\
\text { no. }\end{array}$ & $\begin{array}{l}\text { Concentration } \\
(\mathrm{ppm})\end{array}$ & $\delta^{14} \mathrm{C}(\% o)$ & $\delta^{13} \mathrm{C}(\% \circ)$ \\
\hline $12-1$ & 403.0 & $102 \pm-10$ & -9.23 \\
\hline $12-2$ & 402.5 & & -9.18 \\
\hline $12-3$ & 403.9 & & -9.38 \\
\hline $12-4$ & 403.0 & & -9.23 \\
\hline $12-5$ & 402.7 & & -9.08 \\
\hline $12-6$ & 397.9 & & -9.02 \\
\hline $14-1$ & 394.2 & $104 \pm-11$ & \\
\hline $14-2$ & 393.6 & & -8.81 \\
\hline $14-3$ & 393.6 & & -8.81 \\
\hline $14-4$ & 394.1 & & -8.75 \\
\hline $14-5$ & 393.6 & & -8.74 \\
\hline $14-6$ & 392.9 & & -8.76 \\
\hline $16-1$ & 403.3 & $78 \pm-12$ & \\
\hline $16-2$ & 398.8 & & -9.08 \\
\hline $16-3$ & 397.7 & & -9.02 \\
\hline $16-4$ & 396.8 & & -8.98 \\
\hline $16-5$ & 397.2 & & -8.97 \\
\hline $16-6$ & 398.5 & & -9.05 \\
\hline $18-1$ & 406.5 & $72 \pm-8$ & -9.65 \\
\hline $18-2$ & 406.0 & & -9.60 \\
\hline $18-3$ & 407.0 & & -9.60 \\
\hline $18-4$ & 406.6 & & -9.55 \\
\hline $18-5$ & 408.5 & & -9.61 \\
\hline $18-6$ & 413.6 & & -9.83 \\
\hline $21-1$ & 454.8 & $-54 \pm-9$ & -12.04 \\
\hline $21-2$ & 457.7 & & -12.13 \\
\hline $21-3$ & 461.4 & & -12.25 \\
\hline $21-4$ & 463.6 & & -12.30 \\
\hline $21-5$ & 463.2 & & -12.27 \\
\hline $21-6$ & 463.1 & & -12.24 \\
\hline $24-1$ & 429.3 & $17 \pm-8$ & -10.88 \\
\hline $24-2$ & 433.5 & & -10.99 \\
\hline $24-3$ & & & \\
\hline
\end{tabular}


Table 1 Measured values of concentration, $\delta^{14} \mathrm{C}$ and $\delta^{13} \mathrm{C}$ in atmospheric $\mathrm{CO}_{2}$ (height No. 1: $23.75 \mathrm{~m} ; 2: 19.00 \mathrm{~m}, 3: 14.75 \mathrm{~m}, 4: 9.10 \mathrm{~m}, 5: 5.60 \mathrm{~m}, 6: 1.55 \mathrm{~m}$ )

\begin{tabular}{cccc}
\hline $\begin{array}{c}\text { Time-height } \\
\text { no. }\end{array}$ & $\begin{array}{c}\text { Concentration } \\
(\mathrm{ppm})\end{array}$ & $\delta^{14} \mathrm{C}(\%)$ & $\delta^{13} \mathrm{C}(\%)$ \\
\hline $24-4$ & 442.6 & & -11.24 \\
$24-5$ & 442.0 & & -11.23 \\
$24-6$ & 443.2 & & -11.22 \\
\hline Chukyo TV site (85 m) & & \\
\hline 0 & 400.6 & $71 \pm-6$ & -9.20 \\
6 & 383.8 & $118 \pm-6$ & -8.47 \\
9 & 423.9 & $26 \pm-6$ & -10.53 \\
12 & 389.0 & $103 \pm-6$ & -8.79 \\
15 & 383.9 & $111 \pm-7$ & -8.71 \\
18 & 392.4 & $97 \pm 9$ & -9.12 \\
24 & 427.1 & $13 \pm 7$ & -10.77 \\
\hline
\end{tabular}

